\title{
Crustal deformation associated with the 2011 Shinmoe-dake eruption as observed by tiltmeters and GPS
}

\author{
Hideki Ueda, Tomofumi Kozono, Eisuke Fujita, Yuhki Kohno, Masashi Nagai, Yousuke Miyagi, and Toshikazu Tanada \\ National Research Institute for Earth Science and Disaster Prevention, Tennôdai 3-1, Tsukuba-shi, Ibaraki-ken 305-0006, Japan
}

(Received October 12, 2012; Revised January 8, 2013; Accepted March 2, 2013; Online published July 8, 2013)

\begin{abstract}
The National Research Institute for Earth Science and Disaster Prevention (NIED) developed volcano observation stations at the Kirishima volcanic group in 2010. The stations observed remarkable crustal deformation and seismic tremors associated with the Shinmoe-dake eruption in 2011. The major eruptive activity began with sub-Plinian eruptions (January 26) before changing to explosive eruptions and continuous lava effusion into the summit crater (from January 28). The observation data combined with GEONET data of GSI indicated a magma chamber located about $7 \mathrm{~km}$ to the northwest of Shinmoe-dake at about $10 \mathrm{~km}$ depth. The tiltmeter data also quantified detailed temporal volumetric changes of the magma chamber due to the continuous eruptions. The synchronized tilt changes with the eruptions clearly show that the erupted magma was supplied from the magma chamber; nevertheless, the stations did not detect clear precursory tilt changes and earthquakes showing ascent of magma from the magma chamber just before the major eruptions. The lack of clear precursors suggests that magma had been stored in a conduit connecting the crater and the magma chamber prior to the beginning of the sub-Plinian eruptions.
\end{abstract}

Key words: Shinmoe-dake, Kirishima volcano, tiltmeter, volcanic earthquake, volcanic tremor, eruption, crustal deformation, magma chamber.

\section{Introduction}

The Kirishima volcanic group, southern Kyushu Island, Japan, consists of about 20 volcanoes distributed throughout a long elliptical area about $20 \mathrm{~km}$ wide and $30 \mathrm{~km}$ long and aligned in a northwest-southeast direction (Fig. 1) (Imura and Kobayashi, 1991). After a small eruption at Shinmoe-dake, located at the center of the Kirishima group, on January 19, 2011, major eruptive activity commenced with a small eruption at 07:31 on January 26 (All times listed in this paper are Japan Standard Time, UT $+9 \mathrm{~h}$ ) and intensified to continuous sub-Plinian eruptions at 14:49. The eruption changed to intermittent explosive eruptions on January 27; a lava dome with a diameter of $10 \mathrm{~m}$ appeared in the summit crater on January 28 and its diameter reached $600 \mathrm{~m}$ by February 2.

The volcano observation stations of the National Research Institute for Earth Science and Disaster Prevention (NIED) initiated their operation at the Kirishima volcanic group in 2010. The stations clearly observed seismic activity and crustal deformation related to magma accumulation before the eruption and discharge during the eruption. Following the major eruptions in January and February 2011, which caused damage at and around the volcano (mainly owing to volcanic ash and lapilli), explosive eruptions continued until September 2011; activity has decreased markedly throughout 2012.

Copyright (C) The Society of Geomagnetism and Earth, Planetary and Space Sciences (SGEPSS); The Seismological Society of Japan; The Volcanological Society of Japan; The Geodetic Society of Japan; The Japanese Society for Planetary Sciences; TERRAPUB.

doi:10.5047/eps.2013.03.001
Over the last 300 years, major volcanic eruptions of Shinmoe-dake have occurred in 1717-18, 1771-72, and 1822 (Imura and Kobayashi, 1991). The eruption style and composition of the 2011 eruption have been reported to be similar to those of the 1717-18 eruption (e.g., Geshi et al., 2011; Nakada et al., 2011), in which the largest eruption occurred at the end of the activity, which lasted for one and half years and included intervals of several months of continuous eruption. It is therefore important to monitor the Kirishima group carefully using real-time precise observations. For the efficient monitoring of eruptions and forecasting of future activity based on monitoring data, it is essential to investigate the magma supply system and eruption mechanisms by analyzing observational data from the major eruptions at the beginning of the 2011 activity. The volcano observation stations of NIED succeeded in measuring crustal deformation and earthquakes associated with the sub-Plinian eruptions and continuous lava effusion into the summit crater. Here, we describe the geodetic data of the NIED networks and estimate the magma supply system related to the 2011 Shinmoe-dake eruption by using both NIED data and GEONET data from the Geospatial Information Authority of Japan (GSI), focusing on the major eruptive activity from January 26 to February 2.

\section{The Volcano Observation Network of NIED (V- net)}

We began seismic and geodetic observation at the Kirishima volcanic group using two seismic/deformation stations (KRMV and KRHV) in April 2010 (see Fig. 1(c) for location); both stations are part of the volcano ob- 

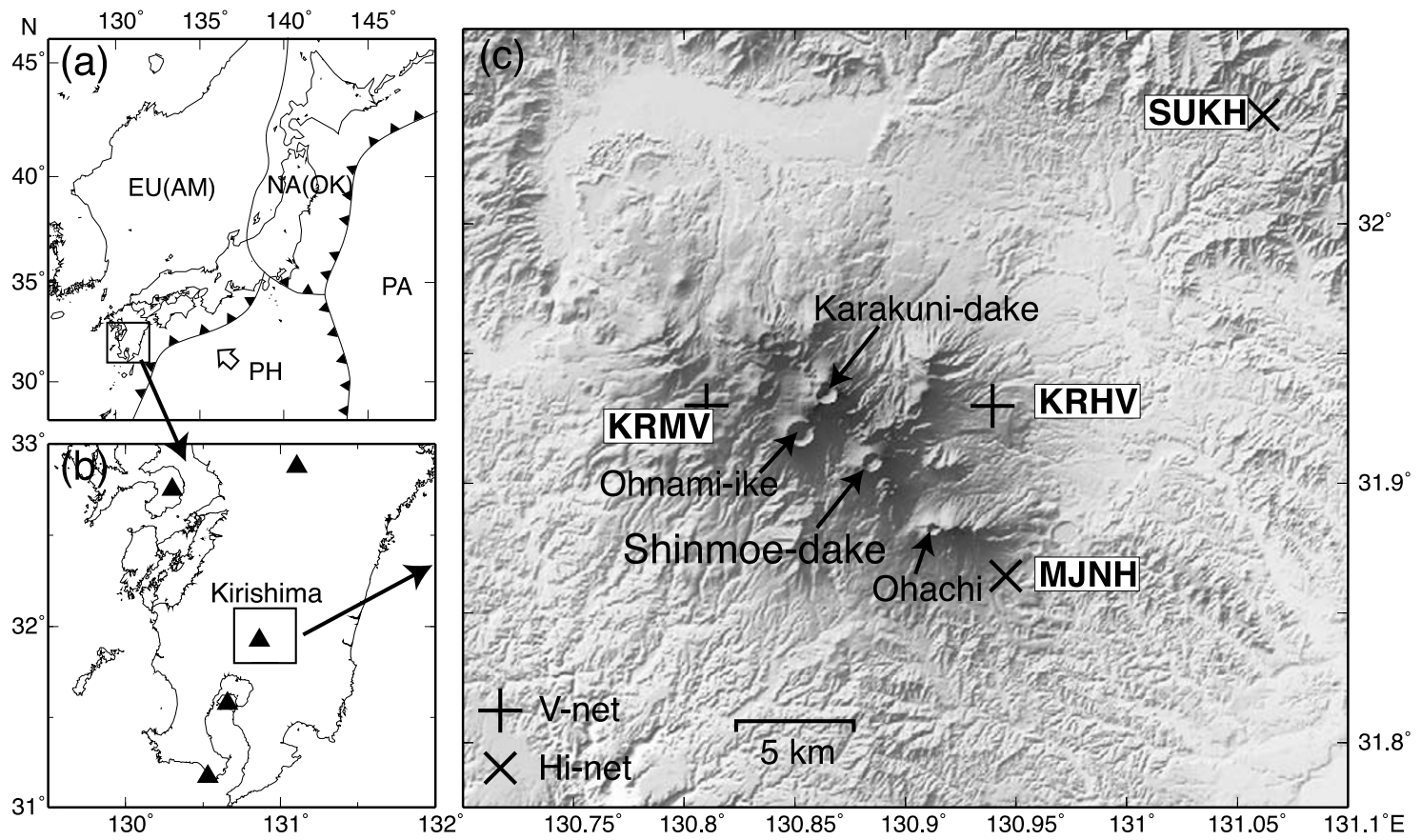

Fig. 1. Location map. (a) Tectonic environment around the Kirishima volcanic group. EU, Eurasian plate; AM, Amurian plate; NA, North American plate; OK, Okhotsk plate; PA, Pacific plate; PH, Philippine Sea plate. Lines show plate boundaries. Open arrow indicates the direction of motion of PH relative to EU (Seno et al., 1993). (b) Location of the Kirishima volcanic group on Kyushu Island. Triangles show active volcanoes. (c) Locations of craters of the Kirishima volcanic group and V-net and Hi-net stations.

servation network (V-net) that NIED began to develop in 2009 to research active volcanoes such as Usu, Iwate, Asama, Kusatsu-Shirane, and Aso. The stations consist of short-period seismometers and pendulum-type tiltmeters (Mitutoyo ABS-143) at the bottom of a borehole $200 \mathrm{~m}$ deep, in addition to broadband seismometers (Nanometrics Trillium-240) and GPS receivers (JAVAD Delta-G3T and RingAnt-DM) on the ground. The dual frequency GPS data are collected with a sampling interval of 30 seconds and downloaded to NIED every hour. We process the coordinates of the GPS stations with the reference frame of ITRF2005 by GAMIT/GLOBK software every day together with the dual frequency GPS data of nearby GEONET stations. The seismometer and tiltmeter data are digitized with sampling frequencies of $100 \mathrm{~Hz}$ and $20 \mathrm{~Hz}$, respectively. The data are transmitted to NIED in real time via an IP-VPN network and are also transmitted to the Japan Metrological Agency (JMA) for volcano monitoring purposes. The real-time observational data from the Shinmoe-dake eruption contributed to volcano warnings and alerts for evacuation of local residents, and the data collection system was commonly used as part of the High Sensitivity Seismograph Network, Japan (Hi-net) operated by NIED. In this paper, we also used data from Hi-net stations SUKH and MJNH (Fig. 1(c)) near the Kirishima volcanic group; these stations are installed with the same types of short-period seismometers and pendulum-type tiltmeters as the other sites, but the instrumentation is located at the bottoms of boreholes $100 \mathrm{~m}$ deep.

\section{Crustal Deformation}

Significant crustal deformation was observed by tiltmeters and GPS at the beginning of the eruptive activity.
Figure 2 shows the one-minute-sampled tiltmeter data from the V-net stations (KRMV and KRHV) and Hi-net stations (MJNH and SUKH) during the period from January 23 to February 2, 2011. We removed tidal components with amplitudes of about $0.1 \mu$ radian using BAYTAP-G (Tamura et al., 1991) and drift components of about $0.02 \mu$ radian/day at the most estimated from the data for the period from January 1 to 25 . The removed components are not significant and well modeled, since the corrected data are almost flat before January 25 and after February 1 in Fig. 2. The three clear steps on January 26 and 27 and the slopelike tilt change during the period from January 28 to 31 correspond to the three sub-Plinian eruptions and the continuous lava effusion into the crater, respectively. Figure 3 shows vector diagrams of the tiltmeter data. Unidirectional tilt toward the area to the northwest of Shinmoe-dake was observed at all four stations; the tilt changes at KRMV, KRHV and MJNH, which are near the volcano, were larger than that at SUKH, which is more distant.

Figure 4 shows the ratio between the magnitude of tilt changes at KRHV compared to those of the other stations over time. No major changes were seen in the ratio during the study period, suggesting that the location and strength of the deformation sources causing the tilt did not vary significantly. Assuming elasticity, the deformation field and the amount of slip or pressurization have a linear relation. For example, synthesized crustal deformation, calculated using both spherical (Mogi, 1958) and dike (Okada, 1992) sources, exhibited a linear relationship with pressure changes but a nonlinear relationship with source location and size. If the depth of the deformation source changes the directions of tilt do not change but the ratio between near and distant stations do. Because of the linear rela- 


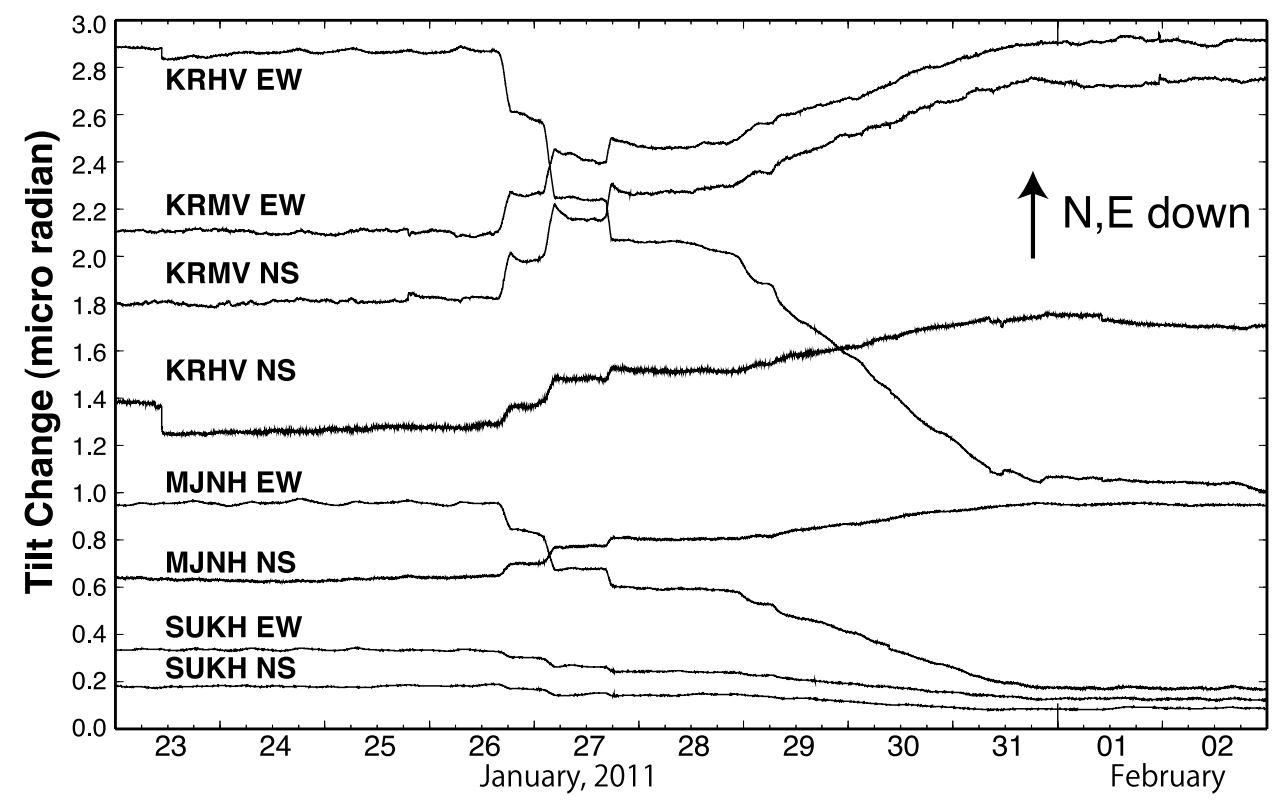

Fig. 2. Tiltmeter data from V-net (KRMV, KRHV) and Hi-net (MKNH, SUKH) stations during the period from January 23 to February 2 , 2011.

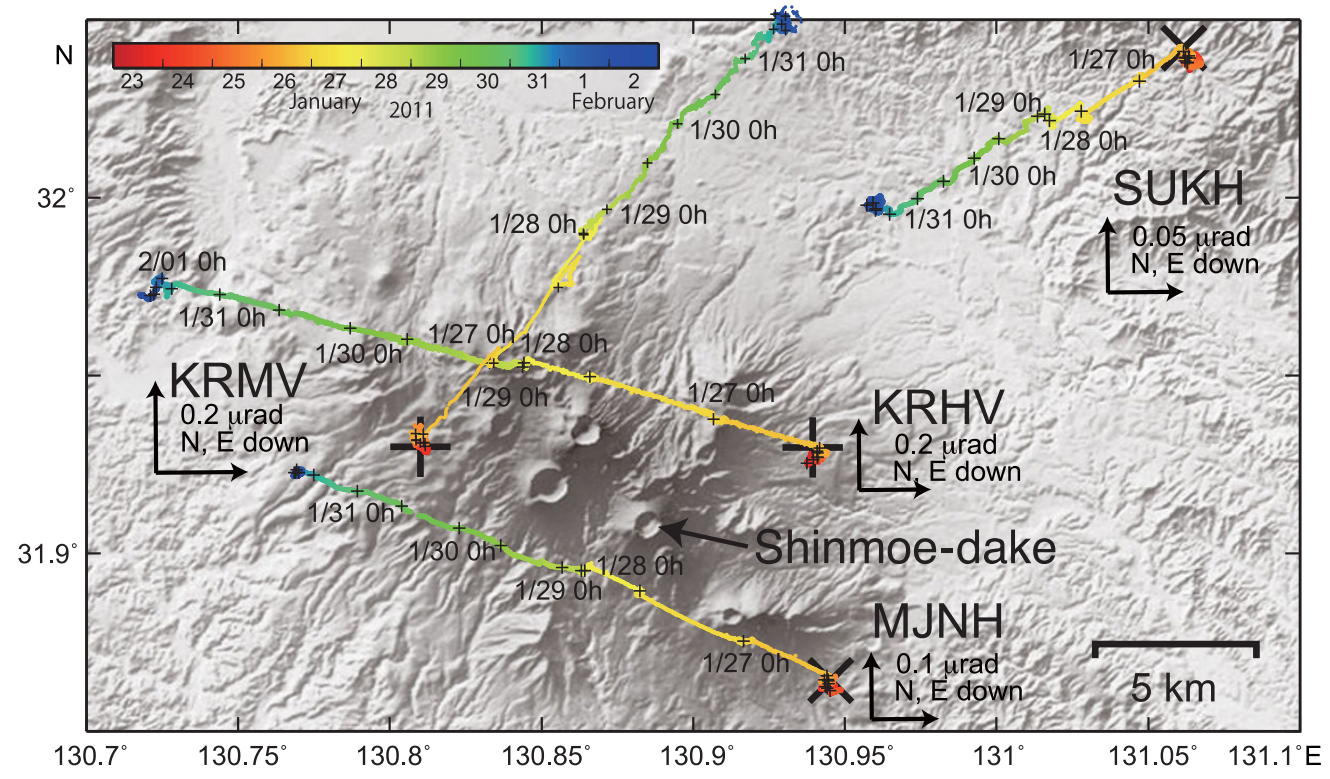

Fig. 3. Vector diagram of maximum tilt direction at V-net (KRMV, KRHV) and Hi-net (MKNH, SUKH) stations during the period from January 23 to February 2, 2011. Crosses are plotted every $12 \mathrm{~h}$.

tion between the deformation field and pressure changes (or amount of dislocationslip) and the nonlinear relation between the deformation field and the source position, the observed unidirectional tilt changes and the steady ratio strongly suggest that the position of the deformation source did not change during the period of interest.

The ratio between KRMV and KRHV exhibited small fluctuations during the step-like tilt changes on January 26 and 27 (see arrows in Fig. 4). Although the ratio of total tilt changes between stations was stable, relatively large steplike tilt changes and subsequent reverse tilt changes were observed at KRMV compared to KRHV. The time series of tilt change for KRMV in Fig. 2 seemed to overshoot during the steps; such tilt changes were seen at only KRMV. No similar deformation is seen at other stations (e.g., Japan
Meteorological Agency, 2011). Since KRMV is the closest station to the modeled deformation source (discussed below), the tilt change of KRMV may contain a local crustal deformation due to the volcanic activity. It is difficult to pursue a physical mechanism of the tilt change, however, because it is observed at only one station (KRMV).

Figure 5 gives the GPS-derived distance change between KRMV and KRHV during April 2010 to August 2012. Extension was observed prior to the eruption but shortening of about $3 \mathrm{~cm}$ occurred at the end of January 2011, when the major explosive eruptions occurred. Extension resumed following January at about the pre-eruption rate and persisted until late 2011. Figures 6(a) and (b) show horizontal and vertical displacements, respectively, from NIED Vnet stations and GEONET stations of GSI relative to the 


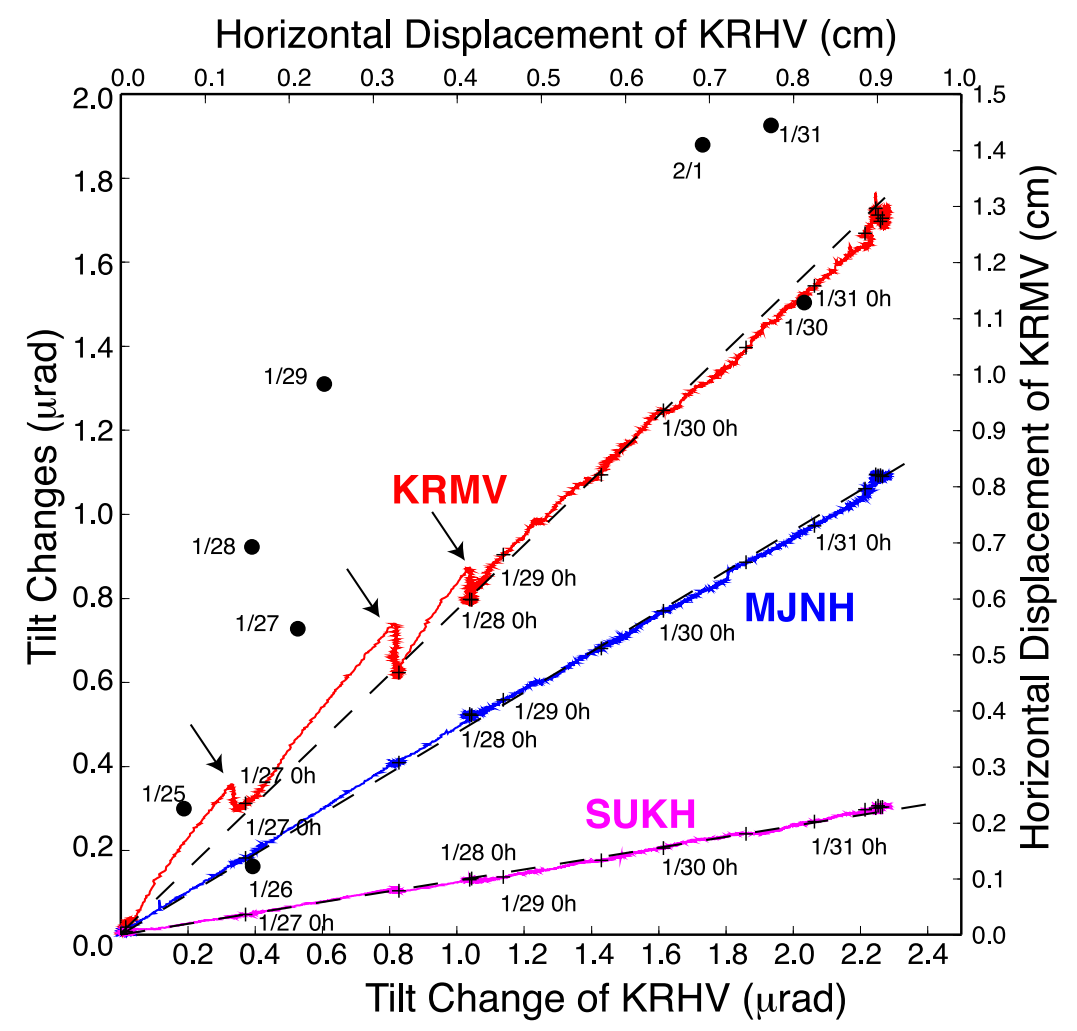

Fig. 4. Comparison of the magnitude of tilt change at KRHV with respect to that at KRMV, MKNH, and SUKH for the period from January 23 to February 2, 2011. Superimposed are lines with the following trends: KRMV/KRHV $=0.77, \mathrm{MKNH} / \mathrm{KRHV}=0.48$, and SUKH/KRHV $=0.13$. Crosses are plotted every $12 \mathrm{~h}$. Arrows indicate small fluctuations during the step-like tilt changes of KRMV. Black circles show the ratio between the magnitude of the horizontal GPS displacements of KRHV and KRMV for the period from January 25 to February 1, 2011.

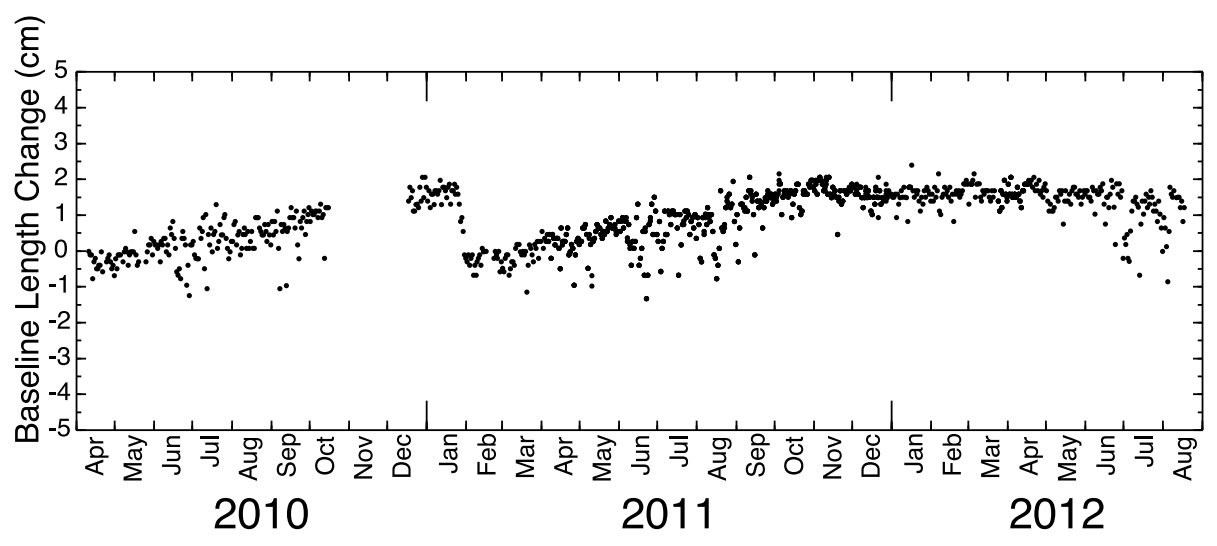

Fig. 5. Baseline length change between KRMV and KRHV, observed by GPS during the period from April 2010 to August 2012.

GEONET Ookuchi station $\left(32.0575^{\circ} \mathrm{N}, 130.5978^{\circ} \mathrm{E}\right)$ during the period from January 25 to February 1 . The displacements and tilt vectors (Fig. 6(c)) indicate deflation and subsidence around an area centered about $7 \mathrm{~km}$ to the northwest of Shinmoe-dake, which probably corresponds to the magma source for the sub-Plinian eruptions and the subsequent lava effusion. We plot the ratio between the magnitude of the GPS-derived horizontal displacements during the period at KRHV and KRMV in Fig. 4 by black circles. Although the ratio of displacements is dispersed, it is almost constant, like that of the tilt changes.

We estimated the deformation source using the GPS and tiltmeter data during the period from January 25 to February 1,2011 . We searched for a best-fit model for the ob- served crustal deformation illustrated in Fig. 6. We tested Mogi models (Mogi, 1958) and dike models (Okada, 1992) and their combinations listed at Table 1, according to the method of Ueda et al. (2005), which is based on a genetic inversion algorism. Models 1 and 2 are single sources, Models 3 and 4 are double sources, and Model 5 is a combination of Mogi and dike sources. We found a single deflating Mogi source to be the best fit model by comparing Akaike's information criterion (AIC) parameters (Akaike, 1974). Figure 6 shows the location of the best-fit Mogi model and observed and modeled deformations, where the deflation volume is $13.2 \times 10^{6} \mathrm{~m}^{3}$ and the depth is $9.8 \mathrm{~km}$. The deflation source was likely a magma chamber feeding the eruptions. The horizontal location is well constrained as 
Table 1. The model parameters of the estimated models.

\begin{tabular}{|c|c|c|c|c|c|c|c|c|}
\hline \multirow{2}{*}{$\begin{array}{l}\text { Model name } \\
\text { Source name }\end{array}$} & \multirow{2}{*}{$\frac{\text { Model } 1}{\text { Mogi }}$} & \multirow{2}{*}{$\frac{\text { Model } 2}{\text { Dike }}$} & \multicolumn{2}{|c|}{ Model 3} & \multicolumn{2}{|c|}{ Model 4} & \multicolumn{2}{|c|}{ Model 5} \\
\hline & & & Mogi 1 & Mogi 2 & Dike 1 & Dike 2 & Mogi & Dike \\
\hline Latitude $\left({ }^{\circ} \mathrm{N}\right)$ & 31.939 & 31.936 & 31.970 & 31.935 & 31.984 & 31.996 & 31.947 & 32.024 \\
\hline Longitude $\left({ }^{\circ} \mathrm{E}\right)$ & 130.822 & 130.850 & 130.870 & 130.814 & 130.865 & 130.880 & 130.872 & 130.807 \\
\hline Depth (km) & 9.8 & 12.2 & 4.6 & 11.3 & 1.1 & 13.4 & 9.8 & 8.9 \\
\hline Strike $\left(^{\circ}\right)$ & - & 8.5 & - & - & 138.4 & 129.9 & - & 123.5 \\
\hline $\operatorname{Dip}\left(^{\circ}\right)$ & - & 152.5 & - & - & 114.4 & 30.4 & - & 89.6 \\
\hline Length (km) & - & 9.9 & - & - & 5.3 & 3.7 & - & 9.8 \\
\hline Width (km) & - & 1.4 & - & - & 9.7 & 9.9 & - & 1.2 \\
\hline Open $(\mathrm{m})$ & - & -1.53 & - & - & -0.08 & -0.55 & - & -1.68 \\
\hline Volumetric Change $\left(10^{6} \mathrm{~m}^{3}\right)$ & -13.2 & - & -2.1 & -11.4 & - & - & -8.5 & - \\
\hline Fitness function & 5.8 & 2.5 & \multicolumn{2}{|c|}{4.8} & \multicolumn{2}{|c|}{1.4} & \multicolumn{2}{|c|}{1.8} \\
\hline $\mathrm{AIC}$ & 32.8 & 44.9 & \multicolumn{2}{|c|}{47.2} & \multicolumn{2}{|c|}{74.4} & \multicolumn{2}{|c|}{59.5} \\
\hline
\end{tabular}

(a) Horizontal Displacement

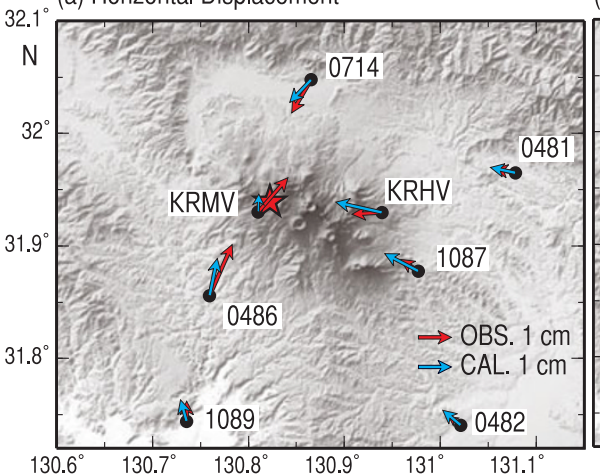

(b) Vertical Displacement

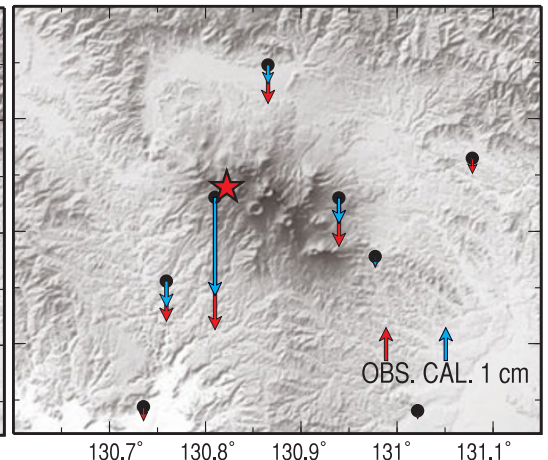

(c) Tilt

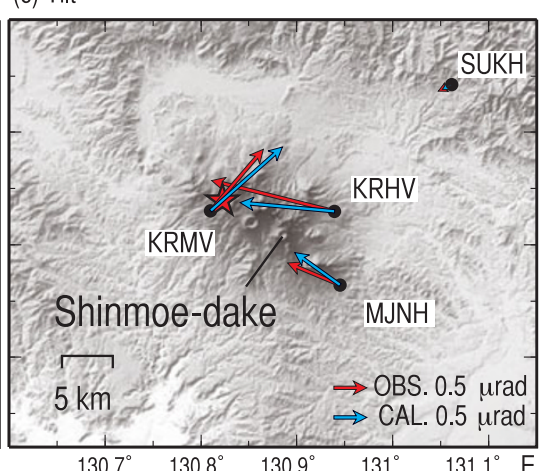

Fig. 6. Comparison of observed crustal deformation (red arrows) with that calculated (blue arrows) by the best-fit Mogi model (red stars). (a) Horizontal displacement vectors from GPS, (b) vertical displacement vectors from GPS, and (c) tilt vectors during the period from January 25 to February 1 , 2011. The displacement vectors are relative to the Ookuchi GEONET station $\left(32.0575^{\circ} \mathrm{N}, 130.5978^{\circ} \mathrm{E}\right)$.

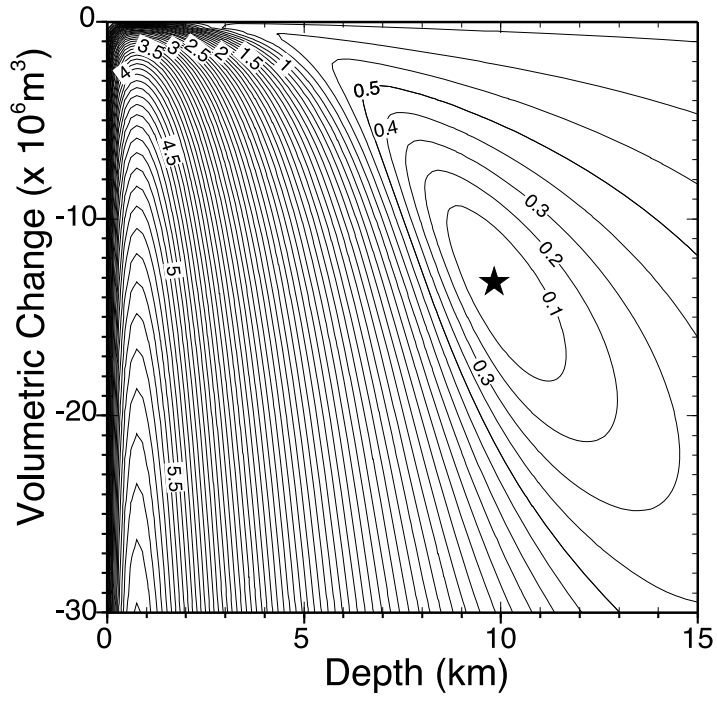

Fig. 7. Contour map of fitness function (Ueda et al., 2005) of model parameters normalized by the minimum value of the fitness function of the best-fit Mogi model (black star) in a model parameter space of depth and volumetric change.

compared with the other parameters, because the tilt change and horizontal displacement vectors points toward an area to the northwest of the Shinmoe-dake crater. Figure 7 shows a contour map of the fitness function of Ueda et al. (2005) normalized by the minimum in a model parameter space of depth and volumetric change. The plot shows a tradeoff between estimated depth and volumetric change. Assuming an area lower than twice of the minimum fitness function (inside the 0.3 contour area in Fig. 7) for the parameter space, the depth and volumetric change have ranges of 7.8$14.5 \mathrm{~km}$ and $-6.0--24.8 \times 10^{6} \mathrm{~m}^{3}$, respectively.

Since the magnitude of deformation is proportional to the volume of deflation (assuming no change in the source position and geometry, as justified above), we consider temporal change in tilt to be proportional to the volume change of the deflation source. Figure 8(a) shows the temporal change of modeled volume based on stacking the tiltmeter data from KRHV and MJNH. Three step-like deflations can be seen for January 26-27; these and the subsequent continuous deflation correspond to the sub-Plinian eruptions and continuous lava effusion, respectively. The deflation volume associated with the sub-Plinian eruptions was $43 \%$ of the total deflation volume $\left(13.2 \times 10^{6} \mathrm{~m}^{3}\right)$-comparable to that of the lava effusion (53\%). The third sub-Plinian eruption was associated with the smallest deflation of the three: deflation during the first and second eruptions were 1.5 and 1.8 times larger than the third, respectively. In addition, the modeled source lost about $4 \%$ of the total deflation volume between the first and second eruptions but did not deflate between the second and third eruptions, indicating that a weak continuous discharge of magma had occurred during the period 


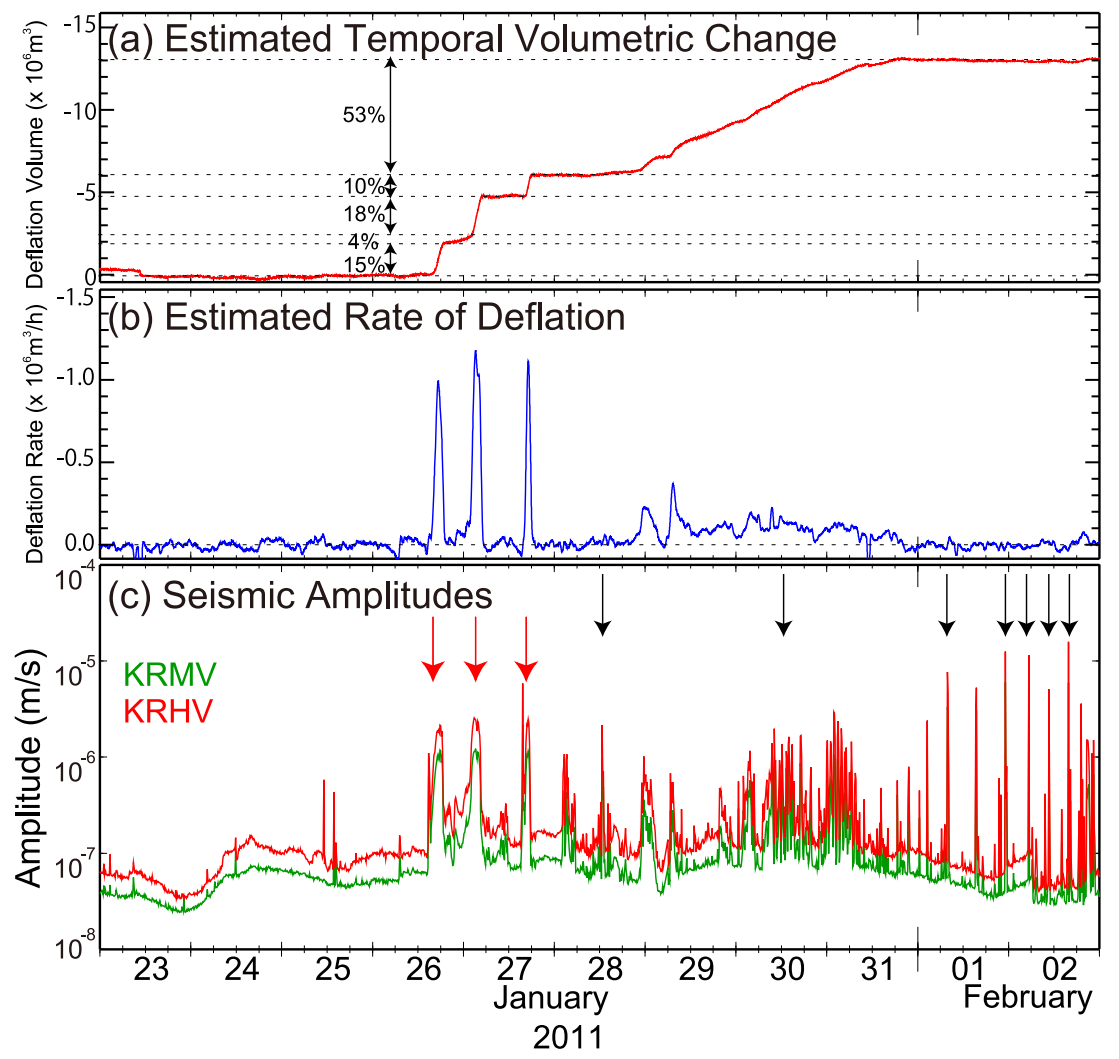

Fig. 8. (a) Temporal modeled volume changes of the magma chamber estimated from tiltmeter data during the period from January 23 to February 2, 2011. Total deflation volume is estimated from tiltmeter and GPS data. The percentage of total deflation volume from each eruption are shown. (b) Modeled deflation rate of the magma chamber by differentiation of the volume changes over time. (c) Temporal changes of 10-min-average seismometer amplitudes at KRMV and KRHV. The red and black arrows indicate the occurrence times of the sub-Plinian and smaller explosive eruptions, respectively.

between the first and second sub-Plinian eruptions.

Figure 8(b) shows the deflation rate of the model magma chamber estimated by differentiation of the temporal volume changes. The three distinct peaks in deflation rate on January 26 and 27 correspond to the three sub-Plinian eruptions. We also note two less distinct peaks during January 28 to 29 , which suggest the occurrence of eruptions. During the period from January 29 to 30 , the deflation continued at a low and almost constant rate. The average modeled deflation rate was $96 \times 10^{3} \mathrm{~m}^{3} / \mathrm{h}$ from 12:00 on January 29 to $12: 00$ on January 31 . The sharp peaks for January 26 and 27 are about ten times larger than the baseline deflation rate. Although the deflation volume associated with each eruption was different, the heights of the peaks are similar. The existence of an upper limit to the deflation rate suggests that the heights of the peaks (i.e., the maximum rate of discharge of magma from the magma chamber) are probably controlled by factors such as magma properties, magma flow rate and vent geometry.

The modeled deflation volume and rate associated with each sub-Plinian eruption act as good indicators of eruption scale and effusion rate. Since the data were collected in real time, rapid estimations of the deflation volume can be used as immediate constraints on the volume and scale of an eruption, which will aid hazard assessment and disaster response. We note that the deflation volume and rate are not equal to erupted volume and rate of discharge of lava from the vent, respectively; such relations depend on the elastic properties and bubble content of magma. Precise estimation of erupted volume and discharge rate of each eruption was conducted by Kozono et al. (2013). They combined the temporal volumetric change of the magma chamber estimated by the geodetic data during the eruption with that of accumulating lava in the crater measured by Synthetic Aperture Radar (SAR) images during the continuous lava effusion. Based on the comparison of these estimated temporal changes of volume, they estimated dense-rock equivalent volumes and discharge rates of magma during the three sub-Plinian eruptions considering magma compressibility and volume variation of a bubble-bearing magma.

The seismicity observed during the eruptions included volcanic tremor, earthquakes associated with explosive eruptions, and harmonic tremor. Figure 8(c) gives 10-min averages of seismometer amplitudes. Although clear seismic activity was observed during each sub-Plinian eruption, we could not detect precursory earthquake activity before the major eruptions beginning on January 26. It is clear that increases in seismic amplitudes due to seismic tremor occurred during the three sub-Plinian eruptions on January 26-27. The seismic amplitude exhibits good agreement with temporal changes in volume and the deflation rate. The seismic tremors associated with the eruptions coincided with the deflation of the magma chamber. Increases in amplitude during January 28-29 also corresponded to increases in the deflation rate, suggesting the occurrence of additional small eruptions. The good agreement indicates 


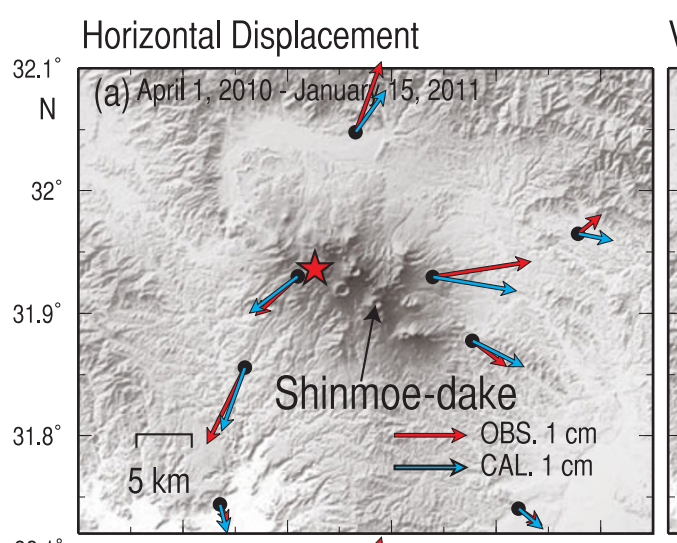

Vertical Displacement

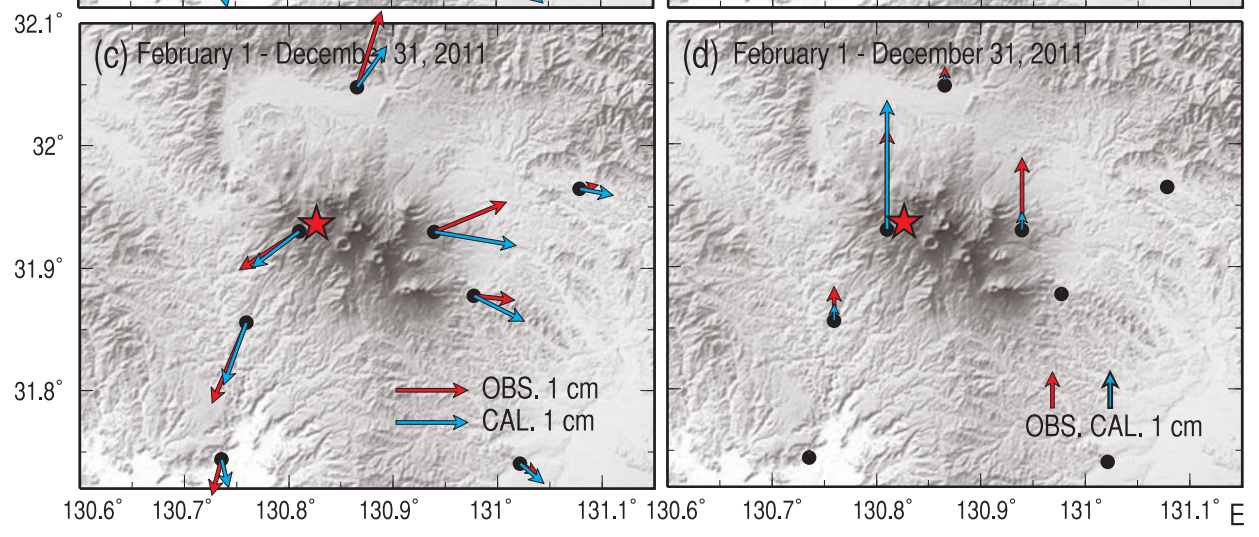

Fig. 9. Comparison of observed crustal deformation (red arrows) with that calculated (blue arrows) from the best-fit Mogi model (red stars). (a) Horizontal and (b) vertical displacement vectors observed by GPS during the period from April 1, 2010 to January 15, 2011. (c) Horizontal and (d) vertical displacement vectors during the period from February 1 to December 31, 2011. The displacement vectors are relative to the Ookuchi GEONET station $\left(32.0575^{\circ} \mathrm{N}, 130.5978^{\circ} \mathrm{E}\right)$.

that volcanic tremor was caused by eruptive activity, such as explosions at the summit and friction between the magma and the conduit wall during magma flow.

\section{Discussion}

The crustal deformation associated with the eruption of Shinmoe-dake indicated the location and possible shape of the magma chamber supplying the eruptive activity. Analysis of co-eruption subsidence and deflation showed a spherical magma chamber located about $7 \mathrm{~km}$ to the northwest of Shinmoe-dake at about $10 \mathrm{~km}$ depth. The magma chamber inflated before and after the eruption, as evidenced by changes in the GPS baseline length between volcano observation stations KRMV and KRHV (Fig. 5). Figure 9 illustrates displacement vectors before and after the eruptions. The displacements exhibit inflation and uplift around an area about $7 \mathrm{~km}$ northwest of Shinmoe-dake, corresponding to an inflation of the magma chamber. The displacements are interpreted by Mogi model at a depth of $6.5 \mathrm{~km}$. The horizontal location is almost the same as the magma chamber estimated from deflation during the sub-Plinian eruptions. Amounts of inflation before (April 1, 2010-January 15, 2011) and after (February 1-December 31, 2011) the eruption were $7.3 \times 10^{6} \mathrm{~m}^{3}$ and $7.1 \times 10^{6} \mathrm{~m}^{3}$, respectively. As mentioned in the previous section, since there is a tradeoff between the estimated depth and volumetric change, they are not well constrained as compared with the horizontal location. The difference in the depth between the deflation source and the inflation source is therefore not significant and we propose that both pre- and post-eruption inflation and co-eruption deformation occurred in the same magma chamber.

Although we have not uncovered any evidence to suggest a conduit connecting the magma chamber to the summit, it is reasonable to assume that the conduit extends linearly from the magma chamber toward the southeast. Imakiire and Oowaki (2011) showed using GPS the existence of a shallow magma chamber at a depth of $3.4 \mathrm{~km}$ beneath Shinmoe-dake crater. They used data of GPS stations deployed near the crater by JMA in addition to GPS data of NIED and GEONET of GSI. The GPS data near the crater provide a more detailed view of a shallow region beneath the crater compared to our model. Their result shows that the deep magma chamber to the northwest of Shinmoe-dake and the shallow chamber were inflated $13.8 \times 10^{6} \mathrm{~m}^{3}$ and $1.2 \times 10^{6} \mathrm{~m}^{3}$, respectively, during the period from December 2009 to January 2011. Therefore, the magma had been stored in these chambers before the beginning of the 2011 eruption, and flowed in a conduit that connects the chambers and the crater during the eruption.

During the eruption, the erupted magma was supplied from the deep magma chamber which is about $7 \mathrm{~km}$ northwest from the Shinmoe-dake crater. Some major craters at Kirishima, such as Karakuni-dake, Ohachi, and Ohnamiike, are situated in the area to the southeast of the modeled magma chamber (Fig. 1(c)). It is not likely that each crater is supplied by a different magma chamber; therefore, the conduit probably branches toward these craters from 


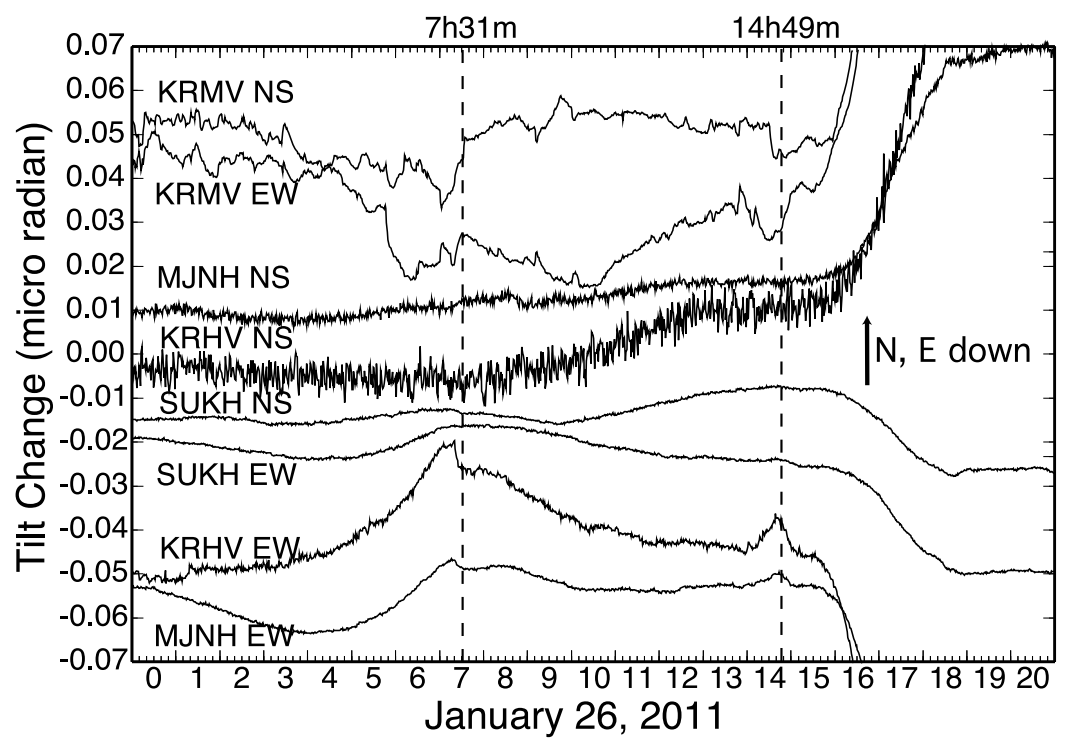

Fig. 10. Enlarged view of tiltmeter data during the period from 0:00 to 21:00 on January 26, 2011. Vertical line shows the occurrence time of the small eruption at 7:31 and the beginning of the sub-Plinian eruption, when the amplitude of the seismic tremor increased at 14:49.

a single zone of magma accumulation. Since the summit crater of Shinmoe-dake has been capped by lava and the deep magma chamber has reinflated since the eruption, it is important to monitor activity not only at Shinmoe-dake but also at the other craters that probably share its magma supply system.

We did not detect clear precursory tilt changes or earthquake activity showing magma ascent from the deep magma chamber just before the sub-Plinian eruptions on January 26-27. Tiltmeters of the type used in this study succeeded in detecting anomalous tilt changes due to a magma movement from a magma chamber to the ground surface in the 1986 Izu-Oshima fissure eruption, and the 1989 Izu-Tobu and 2000 Miyakejima eruptions (Yamamoto et al., 1988; Okada and Yamamoto, 1991; Ueda et al., 2005). Prior to the 2011 Shinmoe-dake eruption, however, we observed only an earthquake related to the small eruption on January 19 and insignificant tilt changes immediately prior to the subPlinian eruptions on January 26-27. Figure 10 shows an enlarged view of one-minute-sampled tiltmeter data at the time of the first sub-Plinian eruption on January 26. The amplitude of the seismic tremor increased at 14:49 and large tilt changes began to occur around 15:30. In addition to small tilt changes associated with the small eruption at 7:31, small tilt changes that began at 14:00 can be seen in the EW components of KRMV and KRHV just before the initiation of the increase in amplitude due to the first sub-Plinian eruption. The small tilt change indicates inflation and subsequent deflation of the summit, suggesting that the change was probably caused by a small eruption on the summit.

The lack of clear precursory tilt changes and earthquakes just before the beginning of the sub-Plinian eruptions suggests that the erupted magma had been gradually ascending from the deep magma chamber toward the crater in the conduit for a long period of time. The GPS observation near the Shinmoe-dake crater shows that the magma accumulated a shallow chamber at the depth of $3.4 \mathrm{~km}$ beneath the Shinmoe-dake crater during the period from December
2009 to January 2011 (Imakiire and Oowaki, 2011). Petrologic investigations of the erupted material related to the small eruption on January 19 indicates that it had the same magma source as the sub-Plinian eruptions (e.g., Geshi et al., 2011), showing the magma had already ascended before the beginning of the sub-Plinian eruptions. Therefore, we probably would not detect precursory tilt changes and earthquakes because the ascending rate of magma was very low as compared with the ascending rates at the beginning of the Izu-Oshima fissure eruption, and the Izu-Tobu and Miyakejima eruptions. The difference between the 2011 Shinmoe-dake eruption without precursory tilt changes and earthquakes and the Izu-Oshima fissure eruption, and the Izu-Tobu, and Miyakejima eruptions are probably due to whether a conduit exists or not. At the beginning of the latter eruptions, the magma ascended abruptly by dike intrusions during the periods of several hours or days (Yamamoto et al., 1988; Okada and Yamamoto, 1991; Ueda et al., 2005). In the case of the 2011 Shinmoe-dake eruption, the magma ascended gradually up the conduit over a period of about 2 years (Imakiire and Oowaki, 2011), and was stored in the conduit and the shallow magma chamber until the beginning of the sub-Plinian eruptions.

\section{Summary}

The NIED V-net stations at the Kirishima volcanic group precisely observed crustal deformation and seismic activity associated with the Shinmoe-dake eruption in 2011. These data, and GEONET data of GSI, indicate the presence of a magma reservoir located about $7 \mathrm{~km}$ to the northwest of Shinmoe-dake and which fed magma to the surface during the sub-Plinian eruptions and the subsequent lava effusion at the summit crater. The observation stations did not exhibit clear precursory signals prior to the major eruptions, suggesting that the erupted magma was stored in a shallow part of an existing conduit that was connected to the deep magma chamber before the beginning of the eruption.

Deformation data indicate the presence of a magma 
chamber; however, the precise characteristics of the conduit that connect the chamber to the surface are still unknown. For monitoring the eruptions of this volcano and forecasting its future activity, it is necessary to investigate the geometry, location, and properties of the conduit and develop techniques for monitoring anomalous changes using observational data from V-net. In addition, both detection of precursory signals and immediate estimations of the location, scale, and type of eruptions, using precise real-time observational data, could contribute to timely hazard assessment and disaster response.

Acknowledgments. We thank Dr. Mike Poland and an anonymous reviewer for their useful comments and language editing which have greatly improved the manuscript. We thank the Geospatial Information Authority of Japan for providing us with GPS data from GEONET and DEM data for the Kirishima volcano.

\section{References}

Akaike, H., A new look at the statistical identification model, IEEE Trans. Autom. Contr., 19, 716-723, 1974.

Geshi, N., G. Saito, A. Tomiya, I. Miyagi, R. Furukawa, S. Nakano, H. Hoshizumi, and H. Takarada, Magma of the January 2011 eruption of Shinmoedake, Kirishima Volcano, Japan Geoscience Union Meeting 2011, SVC050-04, 2011.

Imakiire, T. and A. Oowaki, Source model of Kirishima volcano based on GPS integrated analysis in volcanic region, Journal of the Geospatial Information Authority of Japan, 121, 183-188, 2011 (in Japanese).

Imura, R. and T. Kobayashi, Eruptions of Shinmoedake volcano, Kirishima volcano group, in the last 300 years, Bull. Volc. Soc. Jpn. (Kazan), 36, 135-148, 1991 (in Japanese).

Japan Meteorological Agency, The press release document of the 118th
Coordinating committee for prediction of volcanic eruption on February 15, 2011, 2011.

Kozono, T., H. Ueda, T. Ozawa, T. Koyaguchi, E. Fujita, A. Tomiya, and Y. Suzuki, Magma discharge variations during the 2011 eruptions of Shinmoe-dake volcano, Japan, revealed by geodetic and satellite observations, Bull. Volcanol., 75, 695, doi:10.1007/s00445-013-0695-4, 2013.

Mogi, K., Relations between the eruptions of various volcanoes and the deformations of the ground surface around them, Bull. Earthq. Res. Inst., 36, 99-134, 1958.

Nakada, S. and Joint Observation Team of Kirishima Volcano, Outline and eruptions scenario of the 2011 eruption of Kirishima Volcano, Japan Geoscience Union Meeting 2011, SVC050-01, 2011.

Okada, Y., Internal deformation due to shear and tensile faults in a halfspace, Bull. Seismol. Soc. Am., 82, 1018-1040, 1992.

Okada, Y. and E. Yamamoto, Dyke intrusion model for the 1989 seismovolcanic activity off Ito, central Japan, J. Geophys. Res., 96, 1036110376, 1991.

Seno, T., S. Stein, and A. E. Gripp, A model for the motion of the Philippine Sea Plate consistent with NUVEL-1 and geological data, J. Geophys. Res., 98, 17941-17948, 1993.

Tamura, Y., T. Sato, M. Ooe, and M. Ishiguro, A procedure for tidal analysis with a Bayesian information criterion, Geophys. J. Int., 104, 507-516, 1991.

Ueda, H., E. Fujita, M. Ukawa, E. Yamamoto, M. Irwan, and F. Kimata, Magma intrusion and discharge process at the initial stage of the 2000 Miyakejima activity inferred from tilt and GPS data, Geophys. J. Int., 161, 891-906, 2005.

Yamamoto, E., T. Kumagai, S. Shimada, and E. Fukuyama, Crustal tilt movements associated with the 1986-1987 volcanic activities of IzuOshima volcano-Resutls of continuous crustal tilt observation at Gojinka and Habu—, Kazan, 33, S170-S178, 1988.

H. Ueda (e-mail: ueda@bosai.go.jp), T. Kozono, E. Fujita, Y. Kohno, M. Nagai, Y. Miyagi, and T. Tanada 